\title{
A Qualitative Analysis for Enhancing Competitiveness of Technical and Vocational Colleges in China through Exploring Knowledge Based Intangible Resources
}

\author{
Yong Zhang ${ }^{1,2, *}$, Yusri Kamin ${ }^{2}$ \\ ${ }^{1}$ Guizhou University of Finance and Economics, Guizhou 550025 China; \\ 2 University Teknologi Malaysia, Skudai, Johor Bahru 81310 Malaysia. \\ * Corresponding author
}

Keywords: Competitiveness; Intangible Resources; Qualitative analysis; Technical and vocational Colleges

\begin{abstract}
Competitiveness plays a vital role for technical and vocational colleges to ensure their success and long-term viability. In order to improve competitiveness of technical and vocational colleges in undeveloped areas of China, this paper proposed a new perspective which drew knowledge base view into exploring vocational colleges' resources, specifically intangible resources. Integrated literatures of knowledge-based view and the qualitative findings of perceptions from 15 experts in vocational education or strategic management field, eventually, the paper explored and identified the key components of knowledge-based intangible resources, and also shed light on how these independent variables effect on competitiveness of vocational colleges in undeveloped areas of China. Accordingly, the results support new proposal dimensions of intangible resources that would contribute for vocational colleges improving their competitiveness in management practice, or further academic empirical study.
\end{abstract}

\section{Introduction}

Dating back to the 1980s, colleges and universities began to notice the importance of resources and capacities as rational sources for gaining competitiveness [1]. Interestingly, technical and vocational college (TVC) now widely utilizes multidisciplinary sciences to enhancing competitiveness in very dynamic higher vocational education world. In particular, today's vocational colleges increasingly apply the knowledge based view to explore intangible resources which guarantees them success in competitive education market [2. 3,4]

In general, resources could be classified as tangible resources (TR) and intangible resources (IR). TR consisted of two main important aspects: current and fixed assets. Generally, TR were deemed to directly impact on organisation's capabilities, strategic planning and implementation (Porter, 1980). Nevertheless, many researchers (e.g. Porter, 1998; Mintzberg, 2003; Fathi and Wilson, 2009; Adner and Zemsky, 2013) have documented that TR alone would not be able to maintain competitiveness because they could be easily imitated by rivals. Conversely, IR included brands, trade knowledge, human capital, new technology, culture, policy, etc., as vital and strategic factors in business success, which were more difficult to imitate but are more likely to produce competitiveness. (Barney and Arikan, 2001). Vladimir Kvint (2009) contended that the organisations should expect a sharpened focus on current knowledge based resources necessary to accommodate the development of business and society.

However, today's TVCs are facing many challenges such as globalization, fierce competition, and student/workforce integration. In particular, globalization has led to the changing of the traditional key resources related to competitiveness. Consequently, re-exploring crucial factors, and investigating the interaction of variables has become a complex but significant discipline in the study of TVCs' competitiveness [7]. In the estimation of Hill and Gareth (2012), the basics of competitiveness in today's rapid and unpredictable changing world have been shifting to an emphasis on knowledge based intangible resources. 


\section{Statement of the Problem}

In China, TVC programs are defined as distinctive instruction that contains a series of training programs for young people, adult women and men to learn knowledge and skill from basic to advanced level across a wide range of institutional and work settings and in diverse socio-economic context [3]. However, the importance of intangible resources has yet to be looked at in depth in China's TVCs in most undeveloped areas. The majority of the leaders of TVCs believe that in any competitive landscape, resources (e.g.: capital, buildings, facilities) and capabilities (e.g.: leadership capability, training capability) were most likely to be recognized as important factors for producing CA, because they were the essential components of profit or value. But the leaders of TVCs were generally contented with local government funds and traditional methods of college administration. They paid little attention to developing intangible resources such as campus culture, new technology, knowledge management capability, industrial partnerships, and innovation capacity. Managers in TVCs are still unclear or confused about what are their specific important valuable resources. Specifically, a majority of them have trouble identifying crucial intangible resources. Zhang (2011) stated that there were the huge gaps between TVCs in developed and undeveloped areas in terms of competencies of exploring intangible resources; it can be assumed that the success of attaining a high level of competitiveness among TVCs in undeveloped areas depends largely on the clarity of understanding of key intangible resources among TVCs' managers and lecturers. This presents opportunities for researchers to embark on studies of reorienting key intangible resources that will contribute to enhancing the competitiveness in China.

\section{Literature Review}

\subsection{Resource-Based View (RBV)}

The Resource Based View (RBV) concentrated on organisation's specific resources which include assets, capabilities, organizational processes, attributes, information, and knowledge (Barney, 2010). RBV theory asserted that resources were actually what help a firm exploit opportunities and neutralize threats [2]. Managing strategically according to the RBV involved developing and exploiting an organization's unique resources and capabilities, and continually maintaining and strengthening those resources (Grant 1991). Particularly, Penrose (1959) offered a descriptive logic to demonstrate the causal links between resources, capabilities, and competitiveness, which later transfer to a resource-based theory of competitiveness. In summary, The RBV has continued to grow in popularity and continuous to seek a better understanding of the relationship between resources, capabilities and sustained competitiveness in strategic management. Understanding both resources and capabilities, and more importantly, understanding the relationship between resources and capabilities, between resources, capabilities and CA, were the key to effective achieving and maintaining success[2,6]. Since recourses and capabilities continually change in global knowledge economy era (coulter, 2008), strategy makers saw to identify and take advantage of positive changes and buffer against negative changes in a continuing effort to gain and sustain a firm's competitiveness (David, 2011), and this was the essence and challenge of strategic management, and oftentimes survival of the firm hinged on this work (Fathi and Wilson, 2009).

\subsection{Knowledge Based View (KBV)}

McEvily and Chakravarthy (2009), as well as Miller (2009) further claimed that the organisation could be seen as a knowledge processor able to acquire, integrate, distribute, and recreate knowledge. Lopez (2005) considered knowledge as one key strategic asset to achieve sustained competitive advantage, and organisations gain CA through the process of acquisition, transfer and application of knowledge [8]. Fisher and White (2010), James (2005), and Veugelers (2010), articulated why knowledge-based resources are deemed important for obtaining CA based upon the following three grounds: Firstly, the rapid growth in information and communication technology, together with the high speed knowledge revolution and science advancement, worldwide competition and the variations in the demand of globalization are the reasons that made knowledge a highly important object. Secondly, according to Veugelers, (2010), knowledge is thought to be the most powerful tool of product development. Knowledge capital accumulation will help the advancement in the knowledge-based creativity and innovation. The world is moving towards 
internationalization and a liberalization which allows free movement of capital, workforces and information. Such freedom leads to fierce competition in products or services innovation[7]. Meanwhile, a workforce is the major source of economic prosperity; therefore, it must be given the priority in terms of skill development, knowledge up-gradation and competencies. In order to compete in the rapidly growing, knowledge-based economic environment, transformation towards the knowledge-based view is important because knowledge and information are considered as assets that not only generate prosperity but also make organizations more competitive. Thirdly, in the larger perspective, the overall social economy is based on knowledge, especially that knowledge which can increase competitiveness. In other words, competitiveness is improved through knowledge application rather than through separate attempts to lower labor costs and increase productivity[4,5].

Concentrating on knowledge-based intangible resources in terms of human capital, culture, policy, technology, skills, are conducive to develop dynamic capabilities, such as knowledge management, collaboration, and innovation, then both knowledge-based resources and capabilities as strategically assets could be directed towards improving the RVB framework and contributing to raising the organization's competitiveness [8,9]. Highlighting the significance of the organisation's internal knowledge-based intangible resources as sources of competitive advantage remains undoubtedly, central to an analysis of RBV in the CA studies.

\section{Methodology}

The qualitative research was conducted mainly in three undeveloped provinces (i.e. Sichuan, Guizhou, and Yunnan), involving experts in vocational education or strategy management field. The purpose of qualitative research was to collect enough information or experts perspectives in order to explore key intangible resources and dynamic capabilities which could contribute to competitiveness of vocational colleges in undeveloped areas of China. In order to ensure all participants who were knowledgeable and experienced in strategy management or in higher vocational education, purposive sampling was used to select respondents for the in-depth interview in qualitative research. All participants at least have more 10 years working experience and high level position (professor, associate professor, or top manager). In this research, to ensure the reliability and validity of qualitative research, the interview guide protocol was sent to two experts for review and validation to ensure that the format and contents were in accordance with the qualitative research procedures; each participant checked their transcript; peer evaluations were conducted, i.e., another researcher checked the researcher's inferences based on the instrument; and well as miscellaneous multiple methods, (e.g., more detail description, and conducting a high quality interview) were utilized for accuracy. Due to time and financial constraints, this study only consulted experts in vocational or managerial categories and only 15 experts were involved in this research. Therefore the results may have only been interpreted for TVCs in those undeveloped areas.

\section{Findings and Discussion}

Reviewing those 15 experts in qualitative research, 5 of them were professors in university and have more than 20 years academic experience in strategic management field; among them 8 experts were top managers with more than 10 years working experience in vocational colleges; the rest 2 person were working in ministry of education with top position. In summary they had revealed a number of different definitions and perspectives on intangible resources for vocational colleges.

Based on the integrity analysis of experts' statement, intangible resources (IR) were defined as an identifiable non-monetary asset without physical substances, such as reputation, brand-name, intellectual property. Intangible assets are the long-term resources of an entity, but have no physical existence. The experts note that these identifications of IR premised on seeing IR as key enabler of constructing knowledge management capability, collaboration capability, and innovation. Finally, this study combined broad literatures and experts' perceives of IR for TVC in undeveloped areas, IR could be categorized four dimensions inclusive human capital, college's culture, policies, and information technology(IT) skills. 
Human capital is used in shaping matchless knowledge-based competencies that construct culture and knowledge-based dynamic capabilities that permeate the organisation. In vocational colleges' settings, culture describes not only the value of knowledge but also the internal organisation of this knowledge in order to sustain competitive advantage. Proper culture should be established within vocational colleges to encourage employees and lecturers to create the beliefs, habits, and values to improve dynamic capabilities of knowledge management, collaboration, and innovation among them. Vocational colleges depend heavily on government supports or subsidies, and political forecasts could be the most important part of an external factor. Changes in patent laws, tax rates, and development strategies or regulations also could affect vocational colleges significantly. It is important to highlight that, information technology skill does not assure knowledge management success but plays a crucial role in supporting the entire organisation in its knowledge management initiative.

To sum up, the main theories were used to support the new proposed dimensions of intangible resources which combining with the perspectives of experts view about competitiveness in TVCs, the new proposed dimensions of intangible resources formed. Fig. 1 shows the diagrammatic representation of the proposed conceptual dimensions that may be used to guide for future research of enhancing CA.

\section{Conclusion}

This research proposed a new perspective to explore the competitiveness based on knowledge based resources in vocational colleges. This proposed dimension of intangible resources reoriented the popular theories of competitiveness, and blending with the local experts views. The new dimensions of resources could facilitate the top managers in vocational colleges to identify their knowledge-based intangible resources. It also could be used for further research as guideline. The limitation of this framework is that as a generic framework, it not considered the specificities of each vocational college. For future researches, it could be used as initial framework for the empirical study of competitiveness for TVCs in undeveloped areas of China.

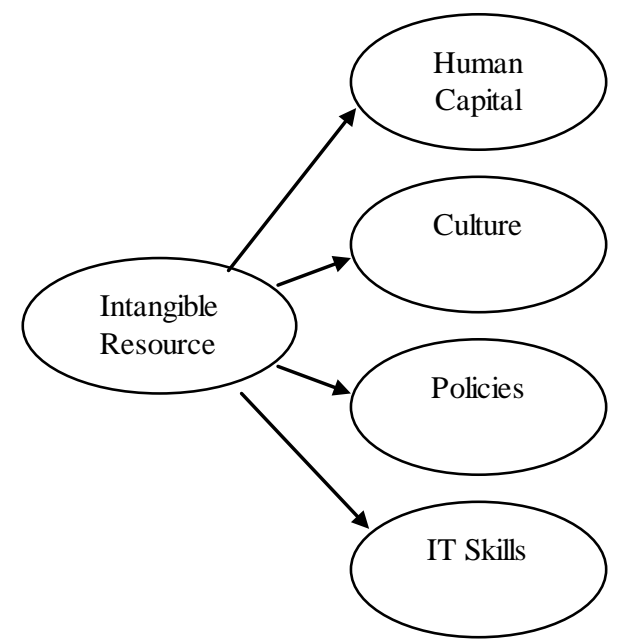

Fig. 1 The Proposed Dimensions of Intangible resources

\section{References}

[1]. Akonkwa, D. B. M., Is market orientation a relevant strategy for higher education institutions? Context analysis and research agenda. International Journal of Quality and Service Sciences, Vol. 1, PP. 311-333. 2009

[2]. Barney, J., Firm Resources and Sustained Competitive Advantage, Journal of management 17 (1), PP. 99-120, 1991. 
[3]. Chinese Ministry of Education (MOE), the Education Development Report of China , Ministry of Education Press. 2014

[4]. Chuang, S-H, A resource-based perspective on knowledge management capability and competitive advantage: an empirical investigation, Expert Systems with Applications, vol. 27, no. 3, pp. 459-65, 2011.

[5]. Ma S.C., Higher Vocational Education: Transfer and Improvement. Beijing: Higher Education Press 2009

[6]. Mahoney, J. T., The Resource-Based View within the Conversation of Strategic Management. Strategic Management Journal 13 (5) pp.363-380, 1995.

[7]. McEvily, SK \& Chakravarthy, B , The persistence of knowledge-based advantage: an empirical test for product performance and technological knowledge', Strategic Management Journal, vol. 23, no. 4, pp. 285-305, 2009.

[8]. Nonaka, I. , The knowledge-creating company, Harvard Business Review, vol. 69, no. 6, pp. 96-104, 1991

[9]. Porter, M. E., Towards a dynamic theory of strategy. Strategic Management Journal, Vol. 12, Special Edition, Winter, pp.95-117, 2003. 